\title{
CORONAL STREAMERS ON THE SUN AND THEIR PHYSICAL PROPERTIES
}

\author{
G. A. Porfir'eva, G. V. Yakunina, A. B. Delone, A. V. Oreshina, I. V. Oreshina \\ State Sternberg Astronomical Institute, \\ Moscow University, Moscow, 119899, Russia, \\ e-mail: galina-porfirieva@yandex.ru
}

(Received January 3, 2009; received in final form May 28, 2009)

\begin{abstract}
A brief review on plasma outflows from coronal streamers is presented. The results of the observations in white-light with coronographs LASCO C2 and C3, in UV-lines with UVCS and EUV-lines with EIT aboard the SOHO during different phases of the solar activity cycle are used. Such events as plasma "blobs" that are elongated plasma flows from streamers and streamer ejection are considered. The velocities of plasma outflowing from streamers increase from $50 \mathrm{~km} \mathrm{~s}^{-1}$ at $3.5 R_{\odot}$ to $300-350 \mathrm{~km} \mathrm{~s}^{-1}$ at $20-25 R_{\odot}$. The behaviour of the temperature $T$, electron density $N_{e}$ and intensity $I$ in coronal streamers and surrounding corona in the range of the heliocentric distances from $1.3 R_{\odot}$ to $5 R_{\odot}$ are discussed. Some physical parameters seem to depend on the phase of the solar cycle. The data from published scientific papers and Internet have been used.

Key words: Sun, corona, streamers, plasma motion.
\end{abstract}

PACS number(s): 96.60.P-

\section{INTRODUCTION}

Streamers are impressive features of the solar corona, distinctly visible at the time of total solar eclipses. During the last decades of the former century they attracted the scientists' attention because of their possible connection with the slow solar wind. Streamers legs and features just above the cusp have been identified with potential sources of the solar wind. Observations from the space made it possible to study physical characteristics and processes in streamers. A variability of coronal plasma properties in an individual streamer and from a streamer to another streamer has been analyzed in [1-7]. There was no clear evidence of a retraction of magnetic field lines in the outer corona until the faint downflows were revealed with the coronograph LASCO C2 SOHO $[8,9]$.

Streamers are coronal features being large-scale closed magnetic structures in the center covered by a blade of open magnetic narrow features. In simple streamers one closed loop system is visible. Complex streamers can form above the complex magnetic structures. In such cases two or more closed systems of the magnetic fields can exist under the shell of the open field. The central streamer part is named streamer core and its flanking open lines are called legs. The flanking magnetic lines meet above the apex of the streamer core forming a cusp and then stretch to far distances from the Sun in the space as narrow coronal features that are known as the so-called coronal rays.

The coronal streamers are well visible on the image of March 29, 2006 total solar eclipse taken by M. Druckmüller and P. Aniol from the Earth and given in [10, Fig. 3]. The streamer rays stretching to $\sim 6 R_{\odot}$ and large helmet streamer at $\mathrm{N}-\mathrm{E}$ quadrant are seen at the eclipse picture cropped at $2.2 R_{\odot}$ and joined to a LASCO C2 image [10, Fig. 4].

The streamers are located above inversion lines of photospheric magnetic lines in active regions or in quiet corona or above quiet prominences and can be divided on active region streamers and quiet streamers. Coronal streamers are believed to be the sources of the slow solar wind (SW). Solar plasma can escape into the space along the open magnetic field lines.

The large-scale structures of the solar corona vary with the eleven-year cycle of the solar activity. During the solar minimum streamers lie close to the solar equator forming the so-called streamer wrinkled belt while they can be seen almost at every latitude during the solar maximum around the whole solar disc as we can see at the time of total solar eclipses. It is seen on Figure 1 [9] where the polarized brightness images of the corona on May 2, 1997 near the minimum of the solar activity and on September 12, 1999 approximately at the solar maximum recorded with the coronograph C2 LASCO SOHO are shown.

The results of observations over streamers with the help of Large Angle Spectrometric Coronograph (LASCO), Ultraviolet Coronograph Spectrometer (UVCS) and Extreme Ultraviolet Imaging Telescope (EIT) aboard the Solar and Heliospheric Observatory (SOHO) are presented. Velocities of the coronal plasma motions at the heliocentric distances $r$ from 2 to $30 R_{\odot}$ can be evaluated. The investigations of physical properties in the streamers (temperatures $T$, electron densities $N_{e}$, and velocities $V_{\text {out }}$ ) are important for the understanding of the role that streamers play in the generation of a slow solar wind.

\section{OBSERVATION AND RESULTS}

\section{A. Plasma outflows from streamers and method}

Investigations of streamers in white-light and ultraviolet spectral lines with the instruments aboard the space observatory SOHO have revealed many new characteristics that were not suspected ealier. LASCO includes two coronographs with separate fields of view: C2 with the space resolution of $24^{\prime \prime}$ and field of view from 
2 to $6 R_{\odot}$ and $\mathrm{C} 3$ with the space resolution of $112^{\prime \prime}$ and field of view from 4 to $30 R_{\odot}$, giving white-light images of the outer corona. The white-light coronal emission, recorded by the LASCO $\mathrm{C} 2$ and $\mathrm{C} 3$, is the photospheric light in the optical region scatterred on a free electron in the solar corona.

The ultra-violet coronograph spectrometer UVCS records profiles of the lines (OVI $1032 \AA, 1037 \AA, \mathrm{H}$ I $L y_{\alpha} 1216 \AA$ ) and images. EIT (Extreme Ultraviolet Imaging Telescope) obtains spectrally resolved images of the solar disc and limb corona to the radial distances of 1.3-1.7 $R_{\odot}$ in the lines of the Fe ions: Fe IX-X $\lambda 171 \AA$, Fe XII $\lambda 195 \AA$, Fe XV $\lambda 284 \AA$. The UV emission lines give a rich information about the dynamics and physical properties in the solar corona. The line profile is a function of the electron temperature $\mathrm{T}$, electron density $N_{e}$, plasma density, outflow (directed) velocity $V_{\text {out }}$ and turbulent component of the plasma velocity.

White-light observations with the LASCO SOHO C2 and C3 have revealed plasma outflows from coronal streamers and their velocities in a projection on the sky plane. Also faint coronal features, moving toward the Sun at the heliocentric distances of $2-6 R_{\odot}$, were observed. Resulting from magnetic reconnection they occur along the bend coronal streamer belt when non-polar coronal holes are subjected to photospheric motions and emergence of new magnetic fluxes have occurred. Such plasma inflows were observed sometimes as frequently as 10-20 per day $[8,9]$.

One typical kind of outflows is the so-called "blobs". Blobs are plasma clouds ejected from the Sun along the streamer axis. As they are denser than the surrounding corona they can be considered as tracers of the slow solar wind. The ejected blobs are connected with the ambient coronal plasma. The solar gravity, magnetic tension and surrounding matter velocities act on them. They become visible at the heliocentric distances of $3-4 R_{\odot}$ and are about of $1 R_{\odot}$ in the length and $0.1 R_{\odot}$ in the width. While blobs flow away their dimensions increase achieving $4 R_{\odot}$ at the heliocentric distances of $12 R_{\odot}$. Observations have shown that the streamers and their cusps are not destroyed by the plasma outflows.

The intensity of the white-light corona decreases quickly with the heliocentric distance. A special method of difference images is used to increase the image contrast. The resulting images are called running difference images. The moving event looks like a "bipolar" feature with a white patch leading the black one in the direction of the blob motion.

The intensity increases in the place where the density increases at a given moment of time and decreases at the site where the density becomes smaller. The plasma blobs ejected from the streamer on February 25, 1997 are seen in Figure 1 (according to Fig. 5 from [11]). The radius of the occulting disc is about $2 R_{\odot}$, and the field of view is up to $6 R_{\odot}$. For the first time the blob appeared at the heliocentric distance of $3.5 R_{\odot}$.

The width of the image of the streamer blobs depends on the inclination of the streamer belt to the line of sight. If the streamer belt is seen from the edge then its image looks as a narrow sheet (like those shown in [11, Fig. 1] for April 23 and February 2, 1997) whereas when a streamer is inclined to the line of sight then its projection on the sky plane seems to be wider (as we can see in the streamer image for January 1, 1997 [11, Fig. 1]).

\section{FEBRUARY 25}

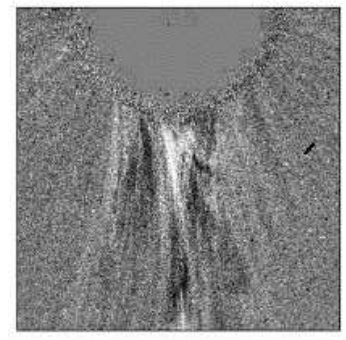

0830 UT

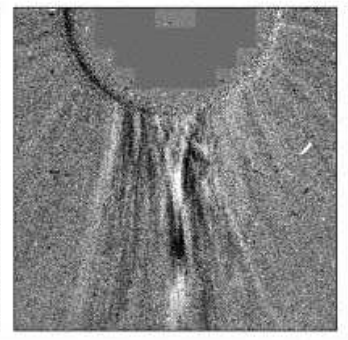

0738 UT

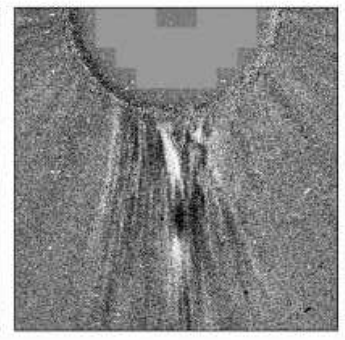

0630 UT

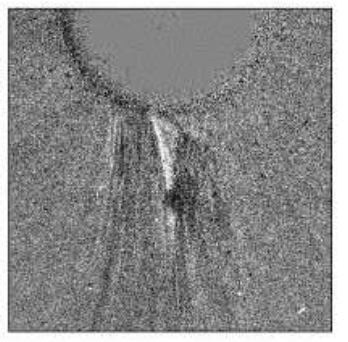

0530 UT

Fig. 1. The plasma blob ejected from the streamer observed in white-light on February 25, 1997 (according to Fig. 5 in [11]).

Maps are constructed on the basis of the running difference images. Radial strips with the width of $10^{\circ}$ centered along the streamer axis are extracted from the $\mathrm{C} 2$ and C3 images and then are oriented vertically one after another in a height-time plot, the time being along the $\mathrm{X}$-axis and heliocentric distances along the $\mathrm{Y}$-axis. The method was proposed by J. H. Walters [12]. Heighttime trajectories of blobs, emitted continuously from the streamer from 19 to 26 April, 1997 show a systematic character of the blob ejections. About 3-5 events per day occur during several days [11]. By analyzing such tracks the dependences of the blobs velocities and accelerations from the heliocentric distances are determined.

We must remember that we have to deal with a projection on the sky plane and so we can derive only a part of the real velocity in the space. Only velocities along a selected radial direction (in a definite position angle) can be determined by this method. We can not 
reconstruct the three-dimensional picture of the streamer blob movement, especially if the plasma cloud has a curved trajectory that really can occur.

Having images simultaneously obtained from two separated in the space cosmic stations we can hope to obtain more realistic knowledge of plasma speeds. Besides, we are to understand that two or more different coronal structures with various velocities and trajectories can exist along the line of sight and so we have a contaminated image. But in fact only coronal structures in limited position angles around the sky plane can be seen because of faint intensities of the events.

In December of 2002 a collaborating study of the streamers at different heights above the solar limb was begun on the basis of the observations of UV spectra of the solar corona. Using the spectral observations with the UVCS the velocities of the outflowing plasma are calculated on the basis of the Doppler dimming effect $[1,2]$.

\section{B. STREAMER CHARACTERISTICS}

A detailed investigation of the variety of plasma properties for a separate streamer in its core and legs were fulfilled on the basis of the observations with UVCS aboard the SOHO. The electron temperature $T_{e}$, kinetic temperature $T_{k}$, electron density $N_{e}$, radial outflow velocities $\mathrm{V}$ and abundances of the elements with the low and high first ionization potentials were obtained in $[1,2,13]$.

The spectral lines of the neutral hydrogen of the Lyman series and OVI $\lambda 1032 \AA$ and $\lambda 1037 \AA$ contain both radiative and collisional contributions. It is possible to separate the contributions knowing the ratios of the intensities of $\operatorname{Ly} \alpha$ to $\operatorname{Ly} \beta$ and OVI doublet lines. The method is described in [2].

The averaged $T_{\mathrm{e}}$ along the line of sight (LOS) is derived by using the intensities of several ions belonging to the same element (similarly to FeX, Fe XXII, Fe XXIII) and the collisional intensity of the $\operatorname{Ly} \beta$ line. The theoretical ratio of the intensities of the $\mathrm{Fe}^{i} / \mathrm{Ly} \beta$ lines is a function of the $T_{\mathrm{e}}$. Knowing observed $R_{o b s}$ and theoretical $R_{t h}$ ratios for three Fe ions as a function of $T_{\mathrm{e}}$ the averaged value for $T_{\mathrm{e}}$ is derived where line curves $\lg \mathrm{R}=\lg \left(R_{\mathrm{obs}} / R_{\mathrm{th}}\right)$ from $\lg \mathrm{T}_{e}$ intercept for three Fe ions. In [1] the average along $\operatorname{LOS} T_{\mathrm{e}}$ for the streamer plasma was equal to $1.75 \pm 0.21 \mathrm{MK}, 1.61 \pm 0.19 \mathrm{MK}, 1.70 \pm 0.21$ MK correspondingly for three different streamers. A supposition of an ideal isothermal plasma was proposed. Indeed some discrete volumes in the solar corona with different $T_{\mathrm{e}}, N_{e}, V_{\text {out }}$ and I exist in the streamer belt and give their own contributions to the observations.

The appearance of the lines of FeXV $\lambda 481 \AA$ and FeXVIII $\lambda 974 \AA$ in UVCS spectra suggest the multithermal streamer plasma presence. Other authors $[3,4]$ have determined the values of $T_{\mathrm{e}}$ in the range from $1.17 \mathrm{MK}$ to $1.66 \mathrm{MK}$ for the heights of $1.5-1.9 R_{\odot}$, including data about the active region and quiet streamers, streamers cores and legs.

No definite regularity has been revealed for the values of the electron temperature $\mathrm{T}_{e}$ for different kinds of streamers and their separate parts. The values of electron densities $N_{e}$ vary in the range from $10^{7}$ to $10^{5} \mathrm{~cm}^{-3}$ when the heliocentric distance increases from $1.75 R_{\odot}$ to $5.0 R_{\odot}[1,2,13]$. In streamers the ratio of the abundance of the low-FIP (first ionization potential) elements to the high-FIP elements has been defined equal approximately to 4 , the value typically found in the slow solar wind $[1,3]$.

As a whole the picture seems complex and not quiet stable. A noticeable variation of the characteristics from a streamer to another streamer and inside the volume of the individual streamer has been revealed. In some quiet streamers cores $T_{e}$ and $N_{e}$ are higher in comparison with the usual quiet streamers. At the same time the streamers observed above ARs have some properties, of typical quiet streamers possessing the core with a low density.

The problem of fine structure of the streamer belt and its variability has remained open. On the one hand, the streamer belt seems to be quasistationary with time. On the other hand it is dynamic. The structure of the streamer belt at far distances from the Sun to the Earth, its modeling and problems of the formation of the solar wind near the solar surface are discussed in [14-18].

\section{STREAMER EJECTION}

Streamer ejection is a special class of the coronal events when as a result of the magnetic reconnection close to the Sun the streamer is suddenly torn and its detachment and subsequent ejection into the interplanetary space occurs $[19,20]$. The low magnetic lines retract to the Sun.

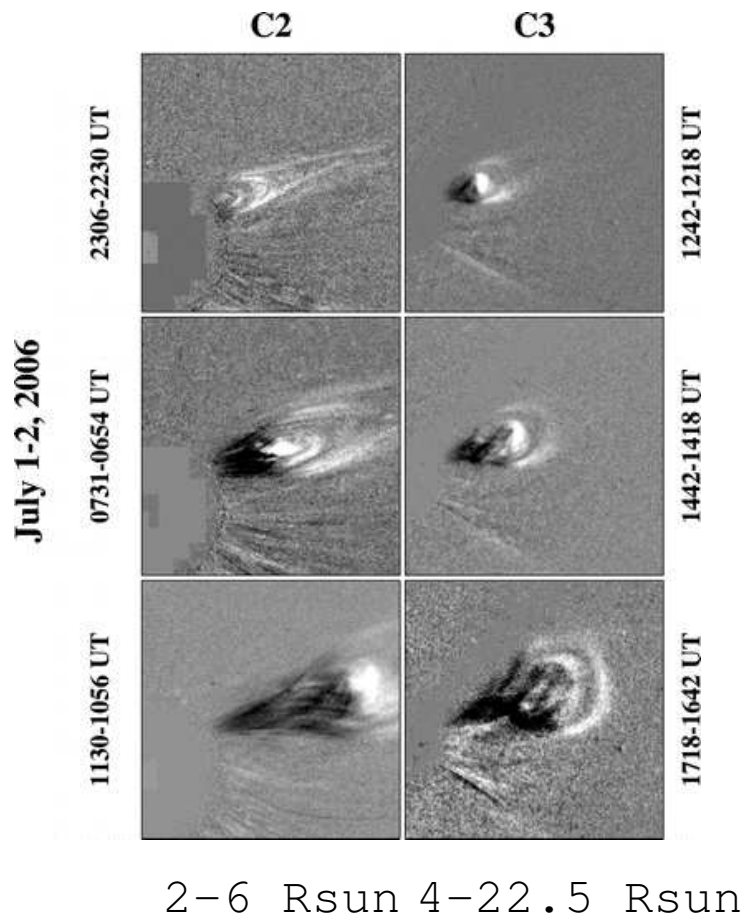

Fig. 2. The streamer ejection observed on July 1-2, 2000 in white-light with the LASCO/SOHO (according to Fig. 1 in [20]). 
In Figure 2 the streamer ejection on July 1-2, 2006 occurring in the $\mathrm{N}-\mathrm{W}$ solar limb is shown. On the left in the C2 coronograph field of view at 23:06 UT an expanding loops system can be seen. The streamer contour is visible as outlined by light lines forming a stretched conus. At 07:31 UT a brightening spot in the center and a dark patch after it appeared. At 11:30 UT streamer legs pinched together. On the right in the C3 coronograph field of view an arched sheath in front of the streamer ejection was forming at 14:42 UT-17:18 UT. It seems to be a bow wave of material swept up when the ejection core was moving through the slower coronal plasma ahead.

Combining the difference images, obtained simultaneously on EIT ( $\lambda 195 \AA$, T $1.3 \mathrm{MK}$ ) and LASCO C2 and C3 (white light) it was revealed that the ejection of the streamer occurred as a result of a reconnection of magnetic field lines close to the Sun at the distances of about of $1.2-1.4 R_{\odot}$. The height-time maps for different position angles allow calculating the velocities and accelerations of different ejected streamer volumes. The averaged velocity increased from $20 \mathrm{~km} \mathrm{~s}^{-1}$ at $3 R_{\odot}$ to $500 \mathrm{~km} \mathrm{~s}^{-1}$ at the distances of $25-30 R_{\odot}$, maximal acceleration was equal to $12 \mathrm{~km} \mathrm{~s}^{-2}$ at the heliocentric distances $8-10 R_{\odot}$.

\section{RESULTS}

Data of the observations of the flow velocities are presented in Table 1. Date is given in the first column, heights of the beginning and end of the events (as heliocentric distances in the solar radii $\mathrm{R}_{\odot}$ ) are presented correspondingly in the second and third columns, upward velocities $V_{\mathrm{ub}}$ at the beginning and $V_{\mathrm{ue}}$ at the end of the observed event are in the fourth and fifth columns, data on the events and instruments are given in the sixth and seventh columns and References are in the last one. The results of the white-light observations with the LASCO C2 and C3, and UV-spectral observations with the UVCS at the solar minimum (1996-1997), near the maximum (October and November 2000) and on the declining branch of the solar activity $(2003,2004)$ are given.

According to the LASCO observations in the whitelight the velocities increase from $50 \mathrm{~km} \mathrm{~s}^{-1}$ at $3.5 R_{\odot}$ to $300-350 \mathrm{~km} \mathrm{~s}^{-1}$ at $20-25 R_{\odot}$ and more. The UVobservations in the OVI $\lambda 1032 \AA, \lambda 1037 \AA$ and $\mathrm{HI} \mathrm{Ly}_{\alpha}$ $\lambda 1216 \AA$ lines give the velocities of the streamer plasma outflows from $20-40 \mathrm{~km} \mathrm{~s}^{-1}$ to $90-140 \mathrm{~km} \mathrm{~s}^{-1}$ in the range of the heliocentric distances from $2.5 R_{\odot}$ to $5 R_{\odot}$. No noticeable differences of the streamer plasma outflows have been revealed at various solar cycle phases.

Data on the velocities in dependence from the heliocentric distances $\mathrm{r} / R_{\odot}$ for 80 blobs observed during 1996 agree well enough with the corona expanding by Parker $\left(T \approx 10^{6} \mathrm{~K}\right)$ as is shown in [9]. The velocities increase from $50 \mathrm{~km} \mathrm{~s}^{-1}$ at $3-4 R_{\odot}$ to $300 \mathrm{~km} \mathrm{~s}^{-1}$ at $20 R_{\odot}$. The velocities determined on the base of the UV spectra in the range from $1.7 R_{\odot}$ to $5 R_{\odot}$ agree with the values obtained in white-light with the LASCO C2.

\begin{tabular}{|c|c|c|c|c|c|c|}
\hline Date & $\begin{array}{c}\text { Height, } \\
R_{\odot}\end{array}$ & $\begin{array}{l}\text { Veloc } \\
\mathrm{km} \mathrm{s} \\
V_{\mathrm{ub}}\end{array}$ & $\begin{array}{c}\text { city } \\
\mathrm{s}^{-1} \\
V_{\text {ue }}\end{array}$ & Event & Instrument & Ref. \\
\hline $24 \mathrm{~V} 1996$ & 5.0 & 120 & 350 & a blob & LASCO & [21] \\
\hline $30 \times 1996$ & $3.7 \quad 20$ & 160 & 310 & a blob & LASCO & [21] \\
\hline 30 IV 1996 & 5.0 & 150 & 360 & a blob & LASCO & [21] \\
\hline 1996 & 2.5 & 50 & 350 & 65 blobs & LASCO & [21] \\
\hline 1996 & $2.5 \quad 29$ & 40 & 360 & 80 blobs & LASCO & {$[9]$} \\
\hline 23-27 IV 1997 & $2.5 \quad 5.0$ & 20 & 89 & outflow & UVCS & [13] \\
\hline $1-2$ VII 2006 & $1.3 \quad 30$ & 20 & 500 & str. eje. & LASCO & [20] \\
\hline $\mathrm{X}-\mathrm{XI} 2000$ & 1.393 .1 & $\leq 50$ & & outflow & UVCS & [22] \\
\hline 28 IV 2003 & $4.0 \quad 5.0$ & 42 & 114 & outflow & UVCS & {$[1]$} \\
\hline $09 \mathrm{~V} 2003$ & $4.0 \quad 5.0$ & 46 & 122 & outflow & UVCS & {$[1]$} \\
\hline 25 IX 2003 & $4.0 \quad 5.0$ & 56 & 144 & outflow & UVCS & [1] \\
\hline $17-22$ V 2004 & $3.5 \quad 5.0$ & 10 & 120 & $\begin{array}{l}\text { OVI line } \\
\text { outflow }\end{array}$ & UVCS & [23] \\
\hline $17-22$ V 2004 & $4.0 \quad 5.0$ & 10 & 60 & $\begin{array}{l}\text { HI line } \\
\text { outflow }\end{array}$ & UVCS & [23] \\
\hline
\end{tabular}

Table 1: Outflow velocities in coronal streamers 


\section{STREAMERS AND DIFFERENT PHASES OF THE SOLAR ACTIVITY}

Investigations of streamers during the solar maximum might be difficult because of the magnetic structure of the corona is more complex and line-of-sight contamination might be strong. Plasma properties in streamers and adjacent regions are generally investigated in the solar minimum [22-26].

In $[22]$ the intensity in streamers (Str) and adjacent regions (Ad Cor) depending on the heliocentric distance is analyzed during different phases of solar activity. UVCSobservations have been used. During the solar minimum the intensity in AdCor decreases with the height more quickly than in the streamer Str. During the solar maximum intensity both in AdCor and in Str decreases in a similar way. The intensity ratio $(2000 / 1997)$ in Adcor and Str differs. Near the Sun streamers are four times brighter during the solar maximum than during the solar minimum and adjacent corona is an order brighter (at the distance of $2.5 R_{\odot}$ ) in the time of the solar maximum in comparison with the minimum.

The kinetic temperature $T_{k}$ is determined from $1 / e$ half-width of coronal line profiles and contains both thermal and non-thermal contributions. The values of the $T_{k}$ are higher in AdCor than in Str and the difference increases with the heliocentric distance in 1997. In 2000 the values of $T_{k}$ in Adcor are higher than in Str by about two times within $2 R_{\odot}$. At greater heights differences vanish. The ratio $T_{k}(2000) / T_{k}(1997)$ is $0.6-0.8$ in Str and 0.8 in AdCor near the Sun $\left(1.8 R_{\odot}\right)$ and decreases in it to $0.3-$ 0.4 at $2.5-3.5 R_{\odot}$. During the solar maximum the electron density $N_{e}$ in Str is higher than during solar minimum by a factor of 4 at $1.7 R_{\odot}$ decreasing to 1 at $3.5 R_{\odot}$.

The results agree with the values of $N_{e}$ determined in $[2,13]$ where it has been shown that the values of the electron density Ne varies in the range from $10^{7}$ to $10^{5} \mathrm{~cm}^{-3}$ within the heliocentric distances from $1.75 R_{\odot}$ to $5.0 R_{\odot}$.
In [23] observations of the OVI and HI UV-lines with the spectrometer UVCS combined with almost simultaneous white-light polarized intensity measurements, made with the LASCO C2 coronograph during a week in May 2004, were analyzed. The outflow velocities in a mid-latitude streamer were determined in the range of the heights from $1.6 R_{\odot}$ to $5 R_{\odot}$. According to the OVI lines the values of the $V_{\text {out }}$ happened to be significantly higher $\left(120 \mathrm{~km} \mathrm{~s}^{-1}\right.$ at $\left.5 R_{\odot}\right)$ in comparison with the values derived from the $\mathrm{HI} \mathrm{Ly} \alpha$ line $\left(60 \mathrm{~km} \mathrm{~s}^{-1}\right.$ at $\left.5 R_{\odot}\right)$. In the authors opinion such a difference is likely due to the mechanism of the absorption of Alfven waves inside the streamer.

\section{SUMMARY}

On the basis of the white-light and EUV spectral observations with the instruments on the SOHO at different phases of the solar activity the velocities of the plasma outflows in streamers have been analyzed near the Sun and to the far heliocentric distances. The velocities increase from several dozen $\mathrm{km} \mathrm{s}^{-1}$ at $2.5-3.5 R_{\odot}$ to $300-$ $400 \mathrm{~km} \mathrm{~s}^{-1}$ at $25-30 R_{\odot}$. A dependence on the phase of the solar activity has not been revealed. For a definite conclusion statistics is not great enough.

Some difference in plasma properties $\left(T_{k}, N_{e}\right)$ in the streamers and adjacent regions during different phases of the solar cycle is likely to be explained by changes both in global magnetic configuration of the corona and in small-scale magnetic structures that causes variations in streamers morphology. The widths of their bases and heights of their cusps change.

Acknowledgments. This work is supported by RFBR grant 08-02-01033-a.
[1] M. Uzzo, L. Strachan, A. Vourlidas, Astrophys. J. 671, $912(2007)$.

[2] M. Uzzo, L. Strachan, A. Vourlidas, Y.-K. Ko, J. C. Raymond, Astrophys. J. 645, 720 (2006).

[3] A. Bemporad, G. Poletto, S. T. Suess, Y. K. Ko, S. Parenti, P. Rilley, M. Romoli, T. Z. Zurbuchen, Astrophys. J. 593, 1146 (2003).

[4] J. C. Raymond, A. Ciaravella, D. Dobrzycka, L. Strachan, Y.-K. Ko, M. Uzzo, Astrophys. J. 597, 1106 (2003).

[5] S. Parenti, B. J. I. Bromage, G. Poletto, G. Noci, J. C. Raymond, G. E. Bromage, Astron. Astrophys. 363, 800 (2000).

[6] J. Li, J. C. Raymond, L. W. Acton, J. L. Kohl, M. Romoli, G. Noci, G. Naletto, Astrophys. J. 506, 431 (1998).

[7] J. C. Raymond et al., Solar Phys. 175, 645, (1997).

[8] N. R. Sheeley, Jr., T. N. Knudson, Y.-M. Wang, Astrophys. J. 546, L131 (2001).

[9] Y.-M. Wang, N. R. Sheeley, Jr., D. G. Socker, R. A. Howard, N. B. Rich, J. Geophys. Res. 105, 25133
(2000).

[10] Y.-M. Wang, J. B. Biersteker, N. R. Sheeley, Jr., S. Koutchmy, J. Mouette, M. Druckmüller, Astrophys. J. 660, 882 (2007).

[11] J.-M. Wang, N. R. Sheeley, Jr., J. H. Walters, G. E. Bruckner, D. J. Michels, P. L. Lamy, Astrophys. J. 498, L165 (1998).

[12] N. R. Sheeley, Jr, J. H. Walters, Y.-M. Wang, R. A. Howard, J. Geophys. Res., 104, 24739 (1999).

[13] L. Strachan, R. Suleiman, A. V. Panasyuk, D. A. Biesecker, J. L. Kohl, Astrophys. J. 571, 1008 (2002).

[14] M. V. Eselevich, V. G. Eselevich, Solar Phys. 188, 299, (1999).

[15] M. V. Eselevich, V. G. Eselevich, Atron. J. 83, 837, (2006)

[16] F. Saez, A. N. Zhukov, P. Lamy, A. Llebaria, Astron. Astrophys. 442, 351 (2005).

[17] F. Saez, A. Llebaria, P. Lamy, D. Vibert, Astron. Astrophys. 473, 265 (2007). 
[18] M. V. Eselevich, V. G. Eselevich, Solar Phys. 235, 331 (2006).

[19] N. R. Sheeley, Jr., Y.-M. Wang, Astrophys. J. 655, 1142 (2007).

[20] N. R. Sheeley, Jr., H. P. Warren, Y.-M. Wang, Astrophys. J. 671, 926 (2007).

[21] N. R. Sheeley, Jr., Y.-M. Wang, S. H. Hawley, G. E. Brueckner, K. P. Dere, R. A. Howard, M. J. Koomen, C. M. Korendyke, D. J. Michels, S. E. Paswaters, D. G. Socker, O. C. St. Cyr, D. Wang, Astrophys. J. 484, 472 (1997).
[22] R. Ventura, D. Spadaro, G. Cimino, M. A. Romoli, Astron. Astrophys. 430, 701 (2005).

[23] D. Spadaro, R. Susino, R. Ventura, A. Vourlidas, E. Landi, Astron. Astrophys. 475, 707 (2007).

[24] G. Noci, J. L. Kohl, G. L. Withbroe, Astrophys. J., 315, 706 (1987).

[25] M. A. Dodero, E. Antonucci, S. Giordano, R. Martin, Solar Phys. 183, 77 (1998).

[26] L. Zangrilli, P. Nicolosi, G. Poletto, G. Noci, M. Romoli, J. L. Kohl, Astron. Astrophys. 342, 592 (1999).

\title{
КОРОНАЛЬНІ ВИКИДИ НА СОНЦІ ТА ЇХНІ ФІЗИЧНІ ВЛАСТИВОСТІ
}

\author{
Г. А. Порфір'єва, Г. В. Якуніна, А. Б. Делоне, А. В. Орєшина, І. В. Орєшина \\ Державний астрономічний інститут імені П. К. Штернберља, \\ Московсъкий університет, Москва, 119899, Росія
}

\begin{abstract}
Зроблено короткий огляд про витікання плазми з корональних стримерів. Використано спостереження у білому світлі на коронографах LASCO C2 і C3, в УФ-лініях на спектрометрі UVCS і далеких УФ-лініях на телескопі ЕIT з борту SOHO під час різних фаз сонячної активності. Швидкості плазми, що витікає зі стримерів, зрозтає від $50 \mathrm{kм} \mathrm{c}^{-1}$ при $3.5 R_{\odot}$ до $300-350 \mathrm{kм} \mathrm{c}^{-1}$ при $20-25 R_{\odot}$. Обговорено поведінку температури $T$, електронної густини $N_{e}$ та інтенсивності $I$ в корональних стримерах і навколишній короні в діапазоні геліоцентричних відстаней від $1.3 R_{\odot}$ до $5 R_{\odot}$. Видається, що деякі фізичні параметри залежать від фази сонячної активності. Використано дані з опублікованих наукових статей та Інтернету.
\end{abstract}

